\title{
Diversity of antisense and other non-coding RNAs in archaea revealed by comparative small RNA sequencing in four Pyrobaculum species
}

\author{
David L. Bernick ${ }^{1}$, Patrick P. Dennis ${ }^{2}$, Lauren M. Lui ${ }^{1}$ and Todd M. Lowe ${ }^{1 *}$ \\ 1 Department of Biomolecular Engineering, University of California, Santa Cruz, CA, USA \\ 2 Janelia Farm Research Campus, Howard Hughes Medical Institute, Ashburn, VA, USA
}

Edited by:

Frank T. Robb, University of California,

USA

Reviewed by:

Mircea Podar, Oak Ridge National

Laboratory, USA

Imke Schroeder, University of

California Los Angeles, USA

Matthias Hess, Washington State

University, USA

Lanming Chen, Shanghai Ocean

University, China

*Correspondence:

Todd M. Lowe, Department of Biomolecular Engineering, University of California, 1156 High Street, Santa Cruz, CA 95064, USA.

e-mail: lowe@soe.ucsc.edu
A great diversity of small, non-coding RNA (ncRNA) molecules with roles in gene regulation and RNA processing have been intensely studied in eukaryotic and bacterial model organisms, yet our knowledge of possible parallel roles for small RNAs (sRNA) in archaea is limited. We employed RNA-seq to identify novel sRNA across multiple species of the hyperthermophilic genus Pyrobaculum, known for unusual RNA gene characteristics. By comparing transcriptional data collected in parallel among four species, we were able to identify conserved RNA genes fitting into known and novel families. Among our findings, we highlight three novel cis-antisense sRNAs encoded opposite to key regulatory (ferric uptake regulator), metabolic (triose-phosphate isomerase), and core transcriptional apparatus genes (transcription factor B). We also found a large increase in the number of conserved C/D box sRNA genes over what had been previously recognized; many of these genes are encoded antisense to protein coding genes. The conserved opposition to orthologous genes across the Pyrobaculum genus suggests similarities to other cis-antisense regulatory systems. Furthermore, the genus-specific nature of these sRNAs indicates they are relatively recent, stable adaptations.

Keywords: antisense small RNA, archaea, transcriptome sequencing, comparative genomics, gene regulation, C/D box small RNA

\section{INTRODUCTION}

Archaeal species are known to encode a plethora of small RNA (sRNA) molecules. These sRNAs have a multitude of functions including suppression of messenger RNA (mRNA; Straub et al., 2009), targeting modifications to ribosomal (rRNA) or transfer RNA (tRNA; Omer et al., 2000; Bernick et al., 2012), specifying targets of the CRISPR immune defense system (Barrangou et al., 2007; Hale et al., 2008; Hale et al., 2009), cis-antisense regulation of transposase mRNA (Tang et al., 2002; Tang et al., 2005; Jager et al., 2009; Wurtzel et al., 2010), and encoding short proteins less than 30 amino acids in length (Jager et al., 2009).

Only a few previous studies have described sRNA genes in the phylum Crenarchaeota. In the Sulfolobus genus, C/D box and H/ACA-box guide sRNAs have been studied, including 18 guide sRNAs in Sulfolobus acidocaldarius (Omer et al., 2000), nine in S. solfataricus (Zago et al., 2005), and corresponding homologs detected computationally in S. tokodaii (Zago et al., 2005). These sRNAs form two distinct classes of guide RNAs: C/D box sRNAs which guide $2^{\prime}-O$-methylation of ribose, and H/ACA-box guide RNAs which direct isomerization of uridine to pseudouridine. Eukaryotes also share these two classes of guide RNAs with the same functions, but these homologs are dubbed small nucleolar RNAs (snoRNAs) because of their cellular localization. Recently, we employed high-throughput sequencing to identify ten conserved, novel families of H/ACA-like sRNA within the genus Pyrobaculum (Bernick et al., 2012).
Sulfolobus solfataricus has been further characterized using high-throughput sequencing (Wurtzel et al., 2010), revealing 18 CRISPR-associated sRNAs, 13 C/D box sRNAs, 28 cis-antisense encoded transposon-associated sRNAs, and 185 sRNA genes encoded antisense to other, non-transposon protein coding genes. It is unclear how many of the latter antisense transcripts are the result of transcriptional noise, overlapping but non-interacting gene products, or biologically relevant products of functional ncRNA genes. The diversity of sRNA genes is just beginning to be studied in depth in other members of the Crenarchaeota.

Genes that produce sRNA antisense to mRNA are known in all three domains of life and many of these sRNA have provided interesting examples of novel regulation. Within bacteria, antisense sRNAs are known and well-studied (Repoila et al., 2003; Aiba, 2007; Vogel, 2009). For example, utilization and uptake of iron in Escherichia coli is modulated by the sRNA RyhB that acts in concert with the ferric uptake regulator (Fur) protein (Masse et al., 2007). The sRNA is coded in trans to its regulatory targets, and the $\mathrm{Sm}$-like protein $\mathrm{Hfq}$ is required for its function. In Pseudomonas aeruginosa, an analogous regulatory mechanism exists with the PrF regulatory RNA (Wilderman et al., 2004).

In this study, we adapted techniques pioneered by researchers studying microRNA in eukaryotes (Lau et al., 2001; Henderson et al., 2006; Lu et al., 2006), to execute parallel high-throughput pyrosequencing of sRNAs across four Pyrobaculum species. This comparative transcriptomic approach enabled us to identify 
novel conserved sRNA transcripts among four related hyperthermophiles (Pyrobaculum aerophilum, P. arsenaticum, P. calidifontis, and $P$. islandicum). We provide an overview of the distribution of sRNAs across species, and focus on two major classes: the highly abundant C/D box sRNAs, and sRNAs antisense to three biologically important protein coding genes. We augment our transcriptional analyses further with comparative genomics utilizing two additional Pyrobaculum species with sequenced genomes: P. neutrophilum (recently renamed from Thermoproteus neutrophilus) and P. oguniense (NCBI GenBank accession NC_016885.1).

\section{MATERIALS AND METHODS CULTURE CONDITIONS}

Pyrobaculum aerophilum cells were grown anaerobically in media containing $0.5 \mathrm{~g} / \mathrm{L}$ yeast extract, $1 \times$ DSM390 salts, $10 \mathrm{~g} / \mathrm{L} \mathrm{NaCl}$, $1 \times$ DSM 141 trace elements, $0.5 \mathrm{mg} / \mathrm{L} \mathrm{Fe}\left(\mathrm{SO}_{4}\right)_{2}\left(\mathrm{NH}_{4}\right)_{2}, \mathrm{pH} 6.5$, with $10 \mathrm{mM} \mathrm{NaNO}_{3}$. P. islandicum and $P$. arsenaticum cells were grown anaerobically in media containing $10 \mathrm{~g} / \mathrm{L}$ tryptone, $2 \mathrm{~g} / \mathrm{L}$ yeast extract, $1 \times$ DSM390 salts, $1 \times$ DSM88 trace elements, and $20 \mathrm{mM} \mathrm{Na}_{2} \mathrm{~S}_{2} \mathrm{O}_{3}$. P. calidifontis cells were grown aerobically in $1 \mathrm{~L}$ flasks using $500 \mathrm{~mL}$ media containing $10 \mathrm{~g} / \mathrm{L}$ tryptone, $2 \mathrm{~g} / \mathrm{L}$ yeast extract, $1 \times$ DSM 88 trace metals, $15 \mathrm{mM} \mathrm{Na}_{2} \mathrm{~S}_{2} \mathrm{O}_{3}, \mathrm{pH} 6.8$, loosely capped with moderate shaking at $125 \mathrm{rpm}$. Anaerobic cultures were grown in $2 \mathrm{~L}$ flasks with $1 \mathrm{~L}$ media, prepared under nitrogen with resazurin as a redox indicator at $0.5 \mathrm{mg} / \mathrm{L} ; 0.25 \mathrm{mM}$ $\mathrm{Na}_{2} \mathrm{~S}$ was added as a reductant. All cultures were grown at $95^{\circ} \mathrm{C}$ to late $\log$ or stationary phase, monitored at $\mathrm{OD}_{600}$.

The $10 \times$ DSM390 salts are comprised of (per liter $\mathrm{ddH}_{2} \mathrm{O}$ ) $1.3 \mathrm{~g}\left(\mathrm{NH}_{4}\right)_{2} \mathrm{SO}_{4}, 2.8 \mathrm{~g} \mathrm{KH}_{2} \mathrm{PO}_{4}, 2.5 \mathrm{~g} \mathrm{MgSO} \cdot 7 \mathrm{H} 2 \mathrm{O}$. The $100 \times$ DSM88 trace metal solution is comprised (per liter $0.12 \mathrm{~N} \mathrm{HCl}$ ), $0.9 \mathrm{mM} \mathrm{MnCl}_{2}, 4.7 \mathrm{mM} \mathrm{Na}_{2} \mathrm{~B}_{4} \mathrm{O}_{7}, 76 \mu \mathrm{M} \mathrm{ZnSO}_{4}, 25 \mu \mathrm{M} \mathrm{CuCl}_{2}$, $12.4 \mu \mathrm{M} \mathrm{NaMoO}, 18 \mu \mathrm{M} \mathrm{VOSO}_{4}, 6 \mu \mathrm{M} \mathrm{CoSO}_{4}$. The $100 \times$ DSM141 trace metal solution is comprised of $7.85 \mathrm{mM}$ Nitrolotriacetic acid, $12.2 \mathrm{mM} \mathrm{MgSO}_{4}, 2.96 \mathrm{mM} \mathrm{MnSO}_{4}, 17.1 \mathrm{mM} \mathrm{NaCl}$, $0.36 \mathrm{mM} \mathrm{FeSO}_{4}, 0.63 \mathrm{mM} \mathrm{CoSO}, 0.68 \mathrm{mM} \mathrm{CaCl}_{2}, 0.63 \mathrm{mM}$ $\mathrm{ZnSO}_{4}, 40 \mu \mathrm{M} \mathrm{CuSO}, 42 \mu \mathrm{M} \mathrm{KAl}\left(\mathrm{SO}_{4}\right)_{2}, 0.16 \mathrm{mM} \mathrm{H}_{3} \mathrm{BO}_{3}$, $41 \mu \mathrm{M} \mathrm{Na}_{2} \mathrm{MoO}_{4}, 0.1 \mathrm{mM} \mathrm{NiCl}_{2}, 1.14 \mu \mathrm{M} \mathrm{Na}_{2} \mathrm{SeO}_{3}$.

\section{CDNA LIBRARY PREPARATION}

Two preparations were constructed for each of $P$. aerophilum, $P$. islandicum, $P$. arsenaticum, and $P$. calidifontis cultures, yielding a total of eight cDNA libraries. The following protocol was used for each preparation.

Total RNA was extracted from exponential or stationary cultures; $100 \mu \mathrm{g}$ of each preparation was loaded onto a $15 \%$ polyacrylamide gel, and size selected in the range 15-70 nt. The gel was post-stained with SYBR Gold and the tRNA band was used as the upper exclusion point. The lower exclusion point was set at $75 \%$ of the region between xylene cyanol (XC) and bromophenol blue (BP) loading dye bands (Ambion protocol). Samples were eluted, EtOH precipitated, and $3^{\prime}$ linker $\left(5^{\prime}\right.$-adenylated, $\left.3^{\prime} \mathrm{ddC}\right)$ was added as described by Lau et al., 2001; IDTDNA, Linker 1). A second gel purification was performed as above, excising the gel fragment above the XC dye band to remove excess $3^{\prime}$ linker. The recovered linked RNAs were reverse transcribed (RT) using Superscript III (Invitrogen) with a DNA primer complementary to Linker 1. Following RT, Exonuclease I (EXO1, Thermo) was added to the RT reaction mixture, and incubated for $30 \mathrm{~min}$ to remove excess primer. We utilized standard alkaline lysis treatment with $\mathrm{NaOH}$-EDTA at $80^{\circ} \mathrm{C}$ for $15 \mathrm{~min}$ to remove any residual RNA, as well as to inactivate the reverse transcriptase and the EXO1 ssDNA nuclease. Neutralization and small fragment removal was performed with water-saturated G50 columns (Ambion NucAway). The recovered single stranded CDNA was dried to near completion using a Servo SpeedVac, followed by a second $5^{\prime}$-adenylated linker addition (IDTDNA - Linker 2) to the CDNA using T4 RNA ligase (Ambion).

A $2 \mu \mathrm{L}$ volume of this reaction was amplified by PCR $(20 \mu \mathrm{L}$ reaction, 16 cycles). This was followed by a second amplification (20 $\mu \mathrm{L}$ reaction, 16 cycles) using $2 \mu \mathrm{L}$ from the first amplification as template using Roche 454-specific hybrid adapters based on the method described by Hannon ${ }^{1}$. A four-base barcode was included in the $5^{\prime}$ hybrid primer. The final reaction was cleaned using the Zymo clean kit following the manufacturer's protocol.

\section{SEQUENCING AND READ MAPPING}

Sequencing was performed using a Roche/454 GS FLX sequencer, and the GS emPCR Kit II (Roche). Sequencing reads described in this work are provided online via the UCSC Archaeal Genome Browser $^{2}$ (Chan et al., 2012).

Reads that included barcodes and sequencing linkers were selected from the raw sequencing data and used to identify reads from each of the eight pooled cDNA libraries. Reads were further consolidated, combining identical sequences with associated counts for viewing with the Archaeal Genome Browser. Reads were mapped to the appropriate genome $[P$. aerophilum (NC_003364.1); P. arsenaticum (NC_009376.1); P. calidifontis (NC_009073.1); P. islandicum (NC_008701.1); P. oguniense (NC_016885.1); P. neutrophilum (T. neutrophilus: NC_010525.1)] using BLAT (Kent, 2002), requiring a minimum of $90 \%$ identity (-minIdentity), a maximal gap of 3 (-maxIntron) and a minimum score (matches minus mismatches) of 16 (-minScore) using alignment parameters for this size range (-tileSize $=8$-stepSize $=4$ ). Reads that mapped equally well to multiple positions in the genome were excluded from this study. The remaining, uniquely mapped reads were formatted and visualized as BED tracks within the UCSC Archaeal Genome Browser.

Of the 216,538 raw sequencing reads obtained, those that had readable barcodes and could be uniquely mapped to their respective genomes were: 39,294 in P. calidifontis, 30,827 in P. aerophilum, 31,206 in P. arsenaticum, and 42,951 in P. islandicum.

\section{NORTHERN ANALYSIS}

Northern blots were prepared using ULTRAhyb-Oligo (Ambion) following the manufacturer protocol ${ }^{3}$ using Hybond-N+ (GE life sciences) membranes to transfer $10 \mu \mathrm{g} / \mathrm{lane}$ denatured total RNA ( $45 \mathrm{~min}, 50^{\circ} \mathrm{C}$ with glyoxyl loading buffer - Ambion). Size separation was conducted using $23 \mathrm{~cm} \times 25 \mathrm{~cm}$ gels $(1 \%$ agarose) in BPTE running buffer $(30 \mathrm{mM}$ bis-Tris, $10 \mathrm{mM}$ PIPES, $1 \mathrm{mM}$ EDTA, $\mathrm{pH}$ 6.5). The following DNA oligomers

\footnotetext{
${ }^{1}$ http://genoseq.ucla.edu/images/a/a9/SmallRNA.pdf

${ }^{2}$ http://archaea.ucsc.edu

${ }^{3}$ http://tools.invitrogen.com/content/sfs/manuals/8663MB.pdf
} 
(Integrated DNA technologies) were used as probes: TFBiiSense (CCTCCTCTGGAAAGCCCCTCAAGCTCCGA), TFBiiAnti (TCGGAGCTTGAGGGGCTTTCCAGAGGAGG), PAEsR53 sense (GACCCCGATCGCCGAAAAATGACGAGTGGT).

\section{COMPUTATIONAL PREDICTION OF ORTHOLOGOUS GENE CLUSTERS}

Computational prediction of orthologous groups was established by computing reciprocal best BLASTP (Altschul et al., 1990; RBB) protein coding gene-pairs among pairs of four Pyrobaculum species. When at least three RBB gene-pairs select the same inter-species gene set (for example A pairs with $B, B$ pairs with $C$, and $\mathrm{C}$ pairs with $\mathrm{A}$ ), the cluster was considered an orthologous gene cluster.

\section{COMPUTATIONAL PREDICTION OF C/D BOX SRNA HOMOLOG FAMILIES}

C/D box sRNA homolog families were constructed from computational predictions with core $\mathrm{C} / \mathrm{D}$ box features that were supported by transcripts from one or more of the four Pyrobaculum species (data from this study). Six Pyrobaculum genomes were searched for orthologs using these sRNA candidates as queries to BLASTN (Camacho et al., 2009). The highest scoring candidates were manually curated, then grouped into homologous C/D box sRNA families by multiple alignment.

\section{RESULTS}

\section{SMALL RNA POPULATIONS}

We prepared eight barcoded sequencing libraries using sRNA fractions (size range 16-70 nt) from anaerobic cultures of $P$. aerophilum, $P$. arsenaticum, $P$. islandicum, and an aerobic culture of $P$. calidifontis. These libraries were prepared using a $5^{\prime}$ independent ligation strategy (Pak and Fire, 2007) which preserves RNA strand orientation, captures both the $5^{\prime}$ and $3^{\prime}$ ends of the sRNA, and does not impose a bias for molecule selection based on 5 '-phosphorylation state. Pyrosequencing, followed by selection of uniquely mapped sequence reads, allowed detection of reads associated with both known and novel genomic features (Figure 1), including:

(i) snoRNA-like guide RNAs, including known and novel C/D box sRNA and a new class of H/ACA-like sRNA (Bernick et al., 2012),

(ii) RNA sequences encoded cis-antisense (asRNA) to known protein coding genes,

(iii) RNA sequences derived from CRISPR arrays, thought to guide the CRISPR-mediated immune response,

(iv) unclassified novel sRNA, and

(v) degradation products of larger RNA including ribosomal RNA, messenger RNA and transfer RNA.

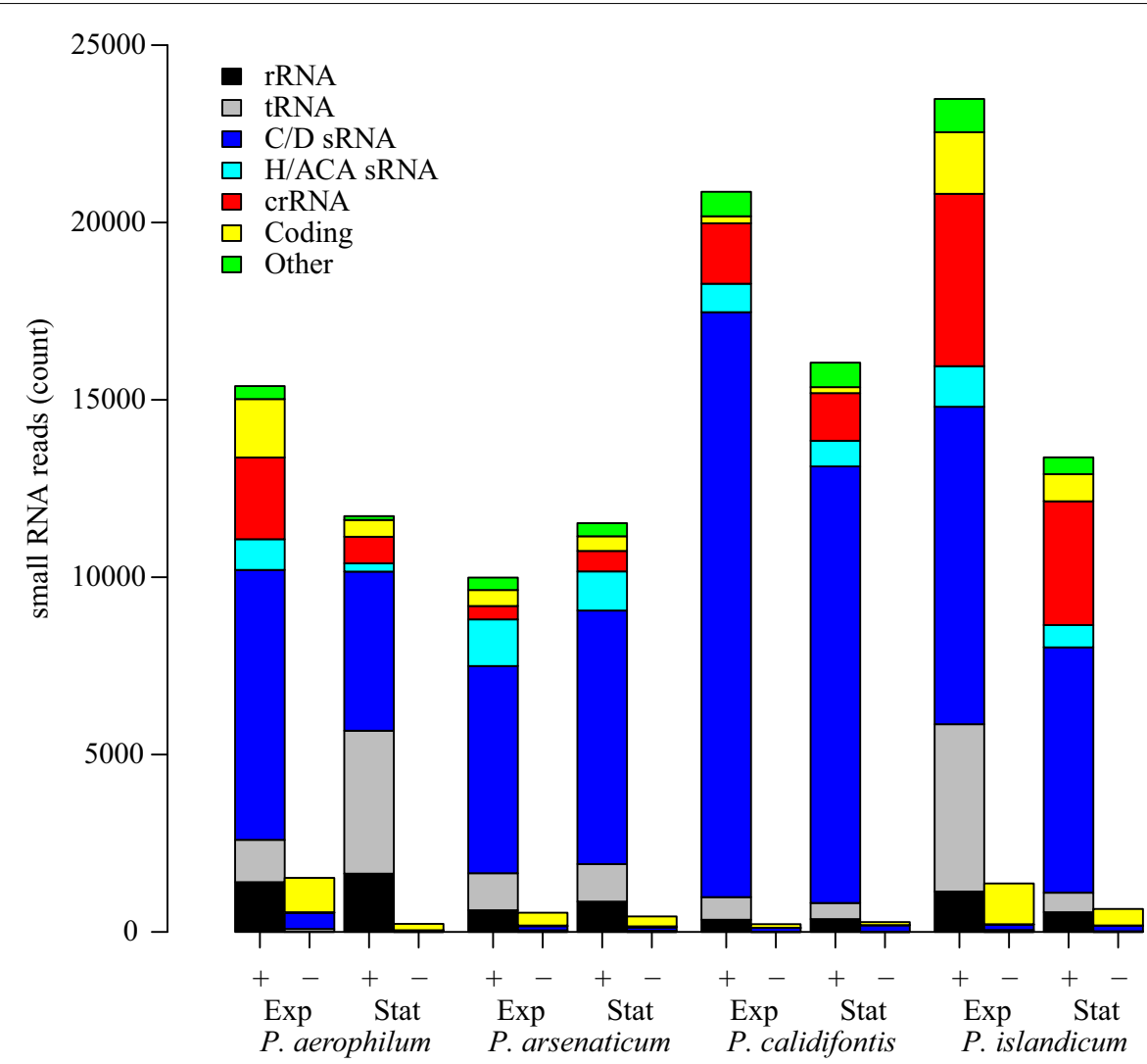

FIGURE 1 | Small RNA transcript abundance in four species of Pyrobaculum. Sense oriented reads $(+)$ and antisense-oriented reads (-) shown in barplots for each species. Samples of each species were taken at both exponential (Exp) and stationary phases (Stat). RNA classifications were made based on mapping to genes coding for $\mathrm{C} / \mathrm{D}$ box sRNA (C/D sRNA), H/ACA-like sRNA, CRISPR arrays (crRNA), fragments of coding regions (coding), ribosomal RNA (rRNA), and transfer RNA (tRNA). 
Most antisense-oriented sequencing reads are associated with coding regions (Figure 1) in each of the species and growth phases examined. Antisense-oriented reads are frequently the result of convergent expression of a protein coding gene and a snoRNA-like guide RNA (Tables A1-A4 in Appendix). We find, in some cases, that sequencing reads that appear to be antisense to snoRNA-like RNAs appear to be fragments of novel $3^{\prime}$ untranslated regions ( $3^{\prime}$ UTRs) of a convergently expressed protein coding region. These antisense-oriented sRNA reads are counted as antisense to the associated snoRNA-like sRNA. We made use of this transcriptional pattern to find novel $\mathrm{C} / \mathrm{D}$ box sRNA and H/ACA-like sRNA; in these cases, highly abundant antisense reads to coding transcripts often proved to be a hallmark of novel C/D box and H/ACA-like sRNA (Tables A2 and A4 in Appendix). In a few remaining cases, we found novel cisencoded antisense reads that were not derived from known classes of sRNA. We note that the proportion of reads belonging to each type of classified RNA is relatively stable across species and conditions (Figure 1), with the exception of two conditions in which tRNA fragments were enriched ( $P$. aerophilum stationary phase, $P$. islandicum exponential phase). We are further investigating these differences, however the purpose and design of the sequencing portion of this study was aimed at qualitative discovery of novel sRNAs.

\section{C/D BOX SRNA ACCOUNT FOR THE LARGEST FRACTION OF READS IN ALL SPECIES TESTED}

In each of the eight small transcriptomes studied (four species sampled at exponential and stationary phase), C/D box sRNA accounted for the largest fraction of reads (Figure 1). A previous study (Fitz-Gibbon et al., 2002) has provided computational evidence for $65 \mathrm{C} / \mathrm{D}$ box sRNA candidates encoded in the genome of $P$. aerophilum. We now find an additional $23 \mathrm{C} / \mathrm{D}$ box sRNA candidates in that genome, representing a $35 \%$ increase in family size. By using transcriptional support from the four examined genomes (this study), combined with comparative genomic evidence that includes $P$. oguniense and $P$. neutrophilum, we find at least $74 \mathrm{C} / \mathrm{D}$ box sRNA in each Pyrobaculum spp. (Table 1). Of those genes, 70 appear to be conserved among all six genomes examined (Figure 2).

Table 1 | C/D box sRNA genes in each Pyrobaculum species based on transcriptional evidence or inferred by homology ( $P$. oguniense and $P$. neutrophilum).

\begin{tabular}{ll}
\hline Species & C/D box sRNAs \\
\hline P. aerophilum & 88 \\
P. arsenaticum & 83 \\
P. calidifontis & 88 \\
P. islandicum & 84 \\
P. oguniense & 83 \\
P. neutrophilum & 74 \\
\hline
\end{tabular}

All loci are manually curated.

\section{CONVERGENTLY ORIENTED ncRNA ARE FREOUENTLY FOUND AT THE 3'} TERMINUS OF PROTEIN CODING GENES

It has been noted previously that in the genomes of $S$. acidocaldarius and $S$. solfataricus, C/D box sRNA genes occasionally exhibit antisense overlap to the $3^{\prime}$ end of protein encoding genes (Dennis et al., 2001). In the Pyrobaculum clade, we find numerous instances of a convergently oriented C/D box or H/ACA-like guide RNA gene that partially overlap, by a few nucleotides, the $3^{\prime}$ end of a protein-coding gene (Tables A2 and A4 in Appendix).

To find conserved, novel cis-encoded antisense RNA, we ranked conserved transcript abundance that overlapped orthologous protein coding genes. Among the top 34 predicted ortholog groups of genes with well-annotated function and conserved $3^{\prime}$ antisense transcription (Table A2 in Appendix), 28 are convergent with C/D box sRNA and three are convergent with H/ACA-like sRNA. Among the top 19 predicted ortholog groups of unknown function with $3^{\prime}$ antisense transcription (Table A4 in Appendix), 11 are convergent with C/D box sRNA, four are convergent H/ACA-like sRNA, and one is adjacent to a tRNA. Together, $87 \%$ of conserved, cis-antisense encoded sRNA are snoRNA-like guides, while only $2.6 \%$ are tRNA. In P. aerophilum, C/D box sRNA genes are nearly twice as abundant ( 88 compared to 46 ) as tRNA genes, but the sRNA genes are over 40-fold more likely to have a conserved overlap with the orthologous protein coding region. This may be an indication that these $\mathrm{C} / \mathrm{D}$ box sRNA play a regulatory role with respect to the associated protein coding genes.

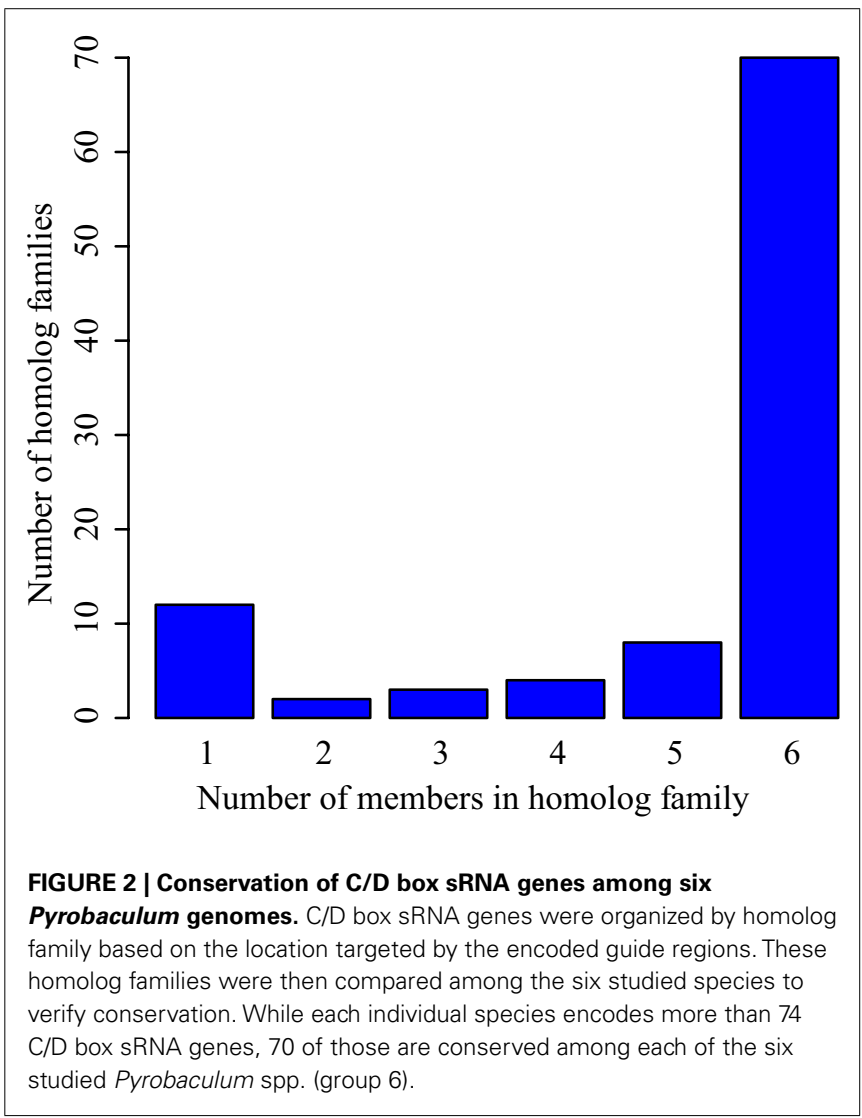


A notable example of a convergent ncRNA occurs at the $3^{\prime}$ terminus of the electron transport flavoprotein (etf) operon, where a C/D box sRNA, PAEsR53, overlaps the terminal gene (PAE0721 in $P$. aerophilum) in this four-gene operon. Like other operons within the Pyrobaculum genus, multiple promoters appear to drive expression of the etf operon (Figure 3). For this operon, an upstream promoter generates a 3400-nt-long full length etfDHferredoxin-etfB-etfA transcript. Two predicted internal promoters appear to generate respectively, the ferredoxin-etfB-etfA $\sim 2250 \mathrm{nt}$ transcript, and the etfA-only $1040 \mathrm{nt}$ transcript.

The $P$. aerophilum sRNA sequencing data revealed a strong abundance of sequences mapping to PAEsR53, as well as sequences of the same general size and location, mapping to the opposite

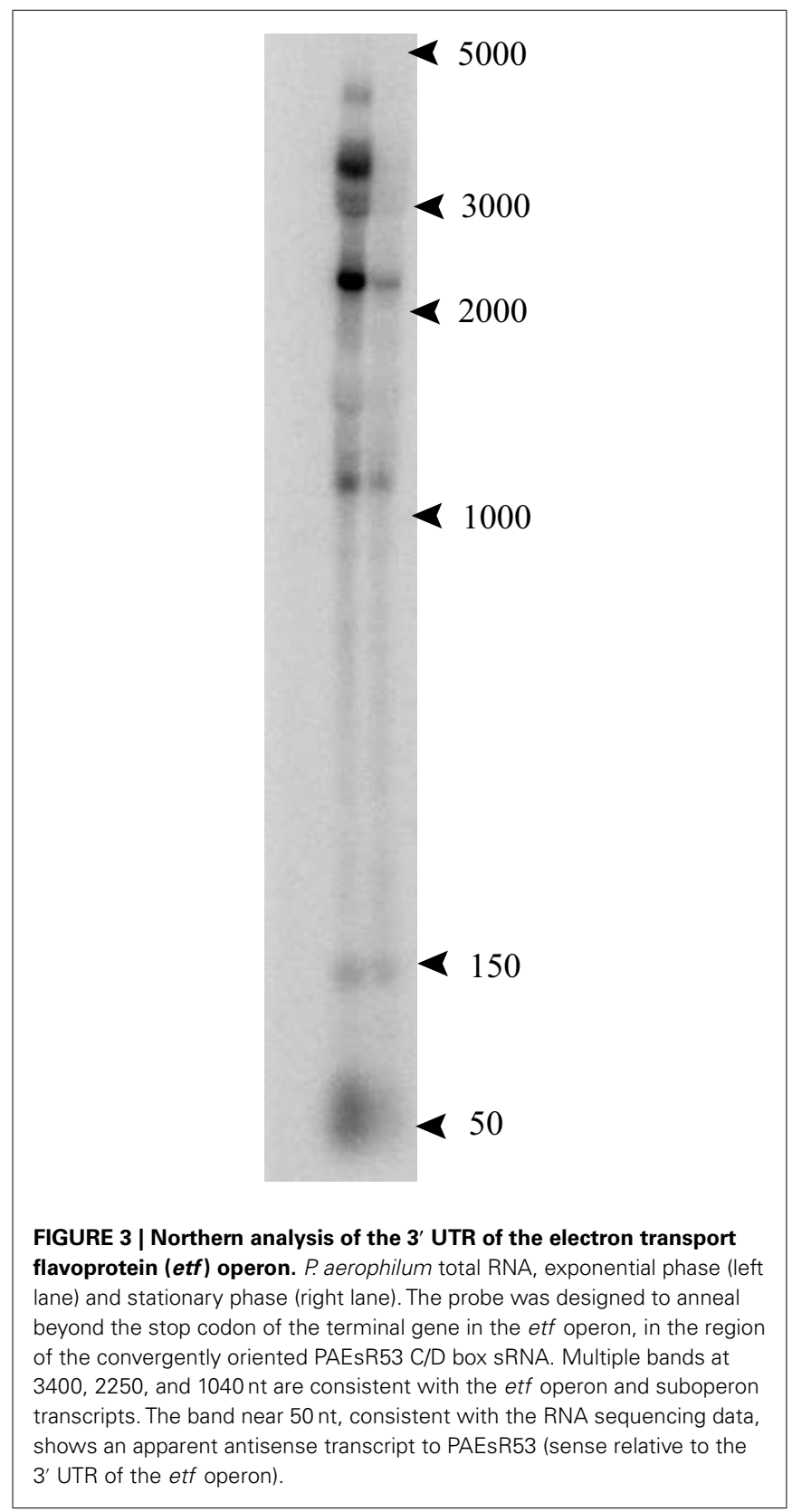

strand (the UTR of the etf operon). Northern hybridization was performed to determine the origin of these "anti-PAEsR53" reads. Figure 3 shows that these reads likely originate from the overlapping $3^{\prime}$ UTR of the etf operon, suggesting a possible interaction of the C/D box machinery with the etf mRNA. Predicted orthologs of this C/D box sRNA (PAEsR53) are syntenic with etfA in all Pyrobaculum species studied, overlapping the $3^{\prime}$ end of etfA orthologs by $\sim 12$ bases. The overlap positions the $\mathrm{D}$ box guide sequence of PAEsR53 over the etfA stop codon in all Pyrobaculum species. If the guide RNA interacts through complementarity with the etfA mRNA, it could enable a $2^{\prime}$-O-methyl modification of the central "A" nucleotide within the conserved TAA stop codon in all four species.

\section{THE TRANSCRIPTION INITIATION FACTOR B GENES, $\boldsymbol{t f b} \mathbf{1}$ AND $\boldsymbol{t} \boldsymbol{f b 2}$}

The genomes of Pyrobaculum species contain a pair of paralogous genes that encode alternate forms of transcription initiation factor B (TFB). This factor is required for the initiation of basal level transcription at archaeal promoters (Santangelo et al., 2007).

In every sequenced Pyrobaculum species, TFB1 (PAE1645 and orthologs) contains a short N-terminal extension (22 amino acids in $P$. aerophilum) that is not present in the TFB2 proteins (PAE3329 and orthologs). Sequencing data reveals the presence of an abundant sRNA (asR1) encoded on the antisense strand that overlaps the $5^{\prime}$ end of $t f b 1$ (Figure 4A) in all four Pyrobaculum species examined (Table A1 in Appendix). Tfb1 also appears to have two promoters separated by $17-18 \mathrm{nt}$, such that the upstream promoter $\left(\mathrm{P}_{\mathrm{u}}\right)$ is positioned to drive expression of full length $t f b 1$, while the downstream promoter $\left(\mathrm{P}_{\mathrm{d}}\right)$ generates transcripts that would lack a start codon near the start of the transcript.

In $P$. aerophilum, asR 1 sRNA is about 59 nt in length (Table 2; Figure 4), with a well-defined $5^{\prime}$ end that overlaps the extension region of the $t f b 1$ gene. The $3^{\prime}$ end of asR 1 is located just upstream of the $t f b 1$ translation initiation codon, precisely at the predicted start of transcription consistent with the $\mathrm{P}_{\mathrm{u}}$ promoter. Importantly, there is an additional set of asR1 sRNA reads of $41 \mathrm{nt}$ in length, starting at the same $5^{\prime}$ position but terminating early, at the $5^{\prime}$ end of $\mathrm{tfb} 1$ transcripts consistent with the alternate $\mathrm{P}_{\mathrm{d}}$ promoter. Mirroring the two variants of the antisense as $R 1$ transcript, deep sequencing revealed a large number of short sense strand sequencing reads, consistent with fragments representing the $5^{\prime}$ end of $t f b 1$ transcripts generated by $\mathrm{P}_{\mathrm{u}}$ and $\mathrm{P}_{\mathrm{d}}$, spanning 50 and $32 \mathrm{nt}$ in length respectively.

Northern analysis of total RNA from P. aerophilum confirmed the presence of a population of sense oriented transcripts of about $1000 \mathrm{nt}$ in length, consistent with full length mRNA and another transcript population consistent with the sense oriented sRNAs described above (Figure 5A). When the antisense sRNA is probed, a population of short transcripts near $50 \mathrm{nt}$ is detected (Figure 5B). The full length sense transcripts appear to be relatively constant in abundance across growth phase and culture conditions, consistent with data from a prior microarray study using the same RNA samples (Cozen et al., 2009). The correlated abundance of sense and antisense sRNA (Figures 5C-E) suggests that these sense::antisense pairs are associated, potentially as a doublestranded RNA. The elevated abundance of these pairs relative to 

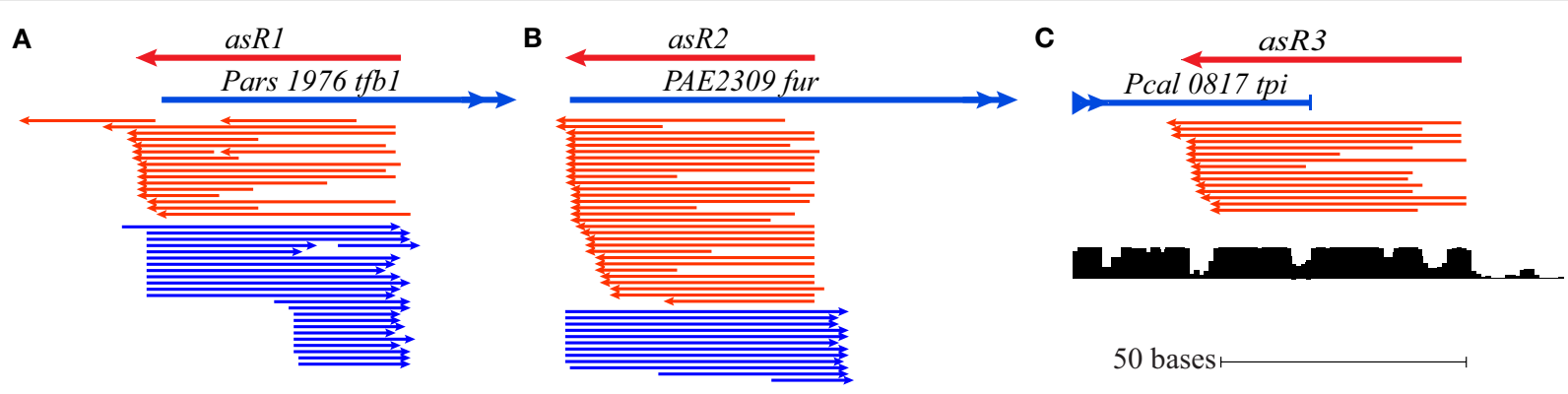

50 bases

FIGURE 4 | Cis-antisense transcription occurring at three conserved loci in Pyrobaculum spp. The antisense sRNA genes (indicated as asR1, asR2, and asR3) are defined over the region of antisense-oriented sequencing reads (shown in red) with the associated gene (sense orientation) shown in blue. (A) Sequencing reads map to the $5^{\prime}$ terminus of transcription initiation factor $B$ in both sense and antisense orientations (Pars_1976 is shown from Pyrobaculum arsenaticum). Sense oriented transcripts (blue) are present in two populations, consistent with the two conserved promoters, $P_{u}$ and $P_{d}$. (B) The antisense sRNA (asR2) gene is defined over the region of antisense-oriented reads that map to the 5 terminus of the ferric uptake regulator gene (fur; PAE2309 from Pyrobaculum aerophilum is shown). (C) Antisense-oriented reads map to the $3^{\prime}$ end of the triose-phosphate isomerase (tpi) locus (Pcal_0817 from Pyrobaculum calidifontis). Sequence conservation [lower graphic (C)] extends beyond the tpi stop codon (UCSC Archaeal Browser; Chan et al., 2012).

Table 2 | Terminal cis-antisense encoded sRNA in Pyrobaculum species.

\begin{tabular}{|c|c|c|c|}
\hline \multicolumn{2}{|c|}{ SRNA } & \multirow{2}{*}{$\begin{array}{l}\text { Len } \\
59\end{array}$} & \multirow{2}{*}{$\begin{array}{l}\text { Sequence } \\
\text { 5'-AACTCGGAGCTTGAGGGGCTTTCCAGAGGAGGGGGGATTTGAGACCGACATAGCGTGTT }\end{array}$} \\
\hline asR1 & Pae & & \\
\hline & Par & 79 & 5' -TATGCGGAGCTTTAGGGGCTTGCCGGAAGAAGGTAGGCTTGTACTCGACATAGCGTGTTTATAAGCTTTTCTAGCGTAT \\
\hline & Pca & 33 & 5' - . TACGGAATTTTAAGGGCTTGCCGGGCGGGGTAG \\
\hline & Pis & 63 & 5' -. ATACGTAGCTTAAGGGGTTTCCCAGAAGACGTCGGACTTGACGACGACATAGCGAGTTTATAA \\
\hline \multirow[t]{2}{*}{ asR2 } & Pae & 60 & 5' -GGGAGTCACTCTGTACCCCCTCTCCTTCAACGCTTGTACTAACTGGGCTGACTCCATCGT \\
\hline & Pca & 54 & $5^{\prime}-\ldots \ldots$ GACGCGGTATCCCTTCTCCTTTAGCGTGGCGACGAGCTGTGCCGTCTCCATAAT \\
\hline \multirow[t]{4}{*}{ asR3 } & Pae & 65 & 5' -ACCCCCGAATTGGGGGCAAATGAGCGGCGGACACTTAAGGCGGCCCCGCCGCGAGCGGTTTCGCC \\
\hline & Par & 58 & $5^{\prime}$-. CCCCCGGA. CGGGGGCGAATGAGCGGCGGGCACCTGTGGCGGCTCCGCCGCGACTACT \\
\hline & Pca & 63 & $5^{\prime}$ - . ACCCCGGA. TGGGGGCGGATGAGCGGCAGACACCTAAGGCGGCCCTGCCGCGACCAAGGGCTT \\
\hline & Pis & 59 & 5' -GACCCCCTGCTGGGGGCATATGAGCGGCGGGCACCTAAGGCGGCTCCGCCGCGACTGTA \\
\hline
\end{tabular}

Position of start codon (on coding strand) shown underlined for asR1 and asR2 (CAT). Position of stop codon (on coding strand) underlined (CTA, TTA) for asR3. Pae (P. aerophilum); Par (P. arsenaticum); Pca (P. calidifontis); Pis (P. islandicum); len (length of sRNA approximated from sequence read population).

the mRNA (Figure 5A) suggests that the sRNA pairs are stabilized within a dsRNA complex. The role of asR1 with respect to $t f b 1$ transcripts is unclear, though the modulation of sRNA (both sense and antisense) while $t f b 1$ mRNA remains at constant and low abundance is reminiscent of negative feedback control.

The presence of complementary sense and antisense transcripts has been observed in a previous RNA sequencing study (Tang et al., 2005). Those authors suggested that the presence of an antisense transcript might enhance the stability of the mRNA target. As exemplified with $t f b l$, the presence of cis-antisense transcripts in our data are often accompanied by the presence of complementary sense strand fragments of similar size. This observation suggests that formation of a dsRNA duplex between the antisense sRNA and the $5^{\prime}$ region of the mRNA target may trigger destabilization of the mRNA; or alternatively, that base pairing between the antisense sRNA and the $5^{\prime}$ end of the nascent mRNA early in elongation may trigger premature transcription termination. For either mechanism, the result appears to be a constant level of $t f b 1$ mRNA under a variety of different culture conditions and growth phases.

\section{THE FERRIC UPTAKE REGULATOR GENE (fur)}

In a number of bacteria, the ferric uptake regulator FUR, is a transcriptional regulator of genes encoding proteins involved in iron homeostasis and protection from the toxic effects of iron under aerobic conditions. Some bacteria also encode a FUR-associated sRNA, for example $r y h B$; its synthesis is negatively regulated by FUR. The $r y h B$ sRNA functions as a negative regulator of genes whose transcription is indirectly activated by FUR. The mechanism of $r y h B$ sRNA negative regulation involves base pairing followed by selective degradation of the targeted mRNA (Andrews et al., 2003).

A homolog of the fur gene is conserved in the genomes of all known Pyrobaculum species. Embedded in each of the associated genes and located about $75 \mathrm{nt}$ downstream from the $5^{\prime}$ start codon is an antisense-oriented, promoter-like sequence. In the two studied facultative aerobes ( $P$. aerophilum and P. calidifontis), we detected a novel 54 nt-long cis-antisense transcript (Table A1 in Appendix), designated as asR2, with precise transcription initiation consistent with the noted antisense promoter-like sequence. The $3^{\prime}$ end of the asR2 transcript (Table 2; Figure 4B) transcript 
A probe of sense

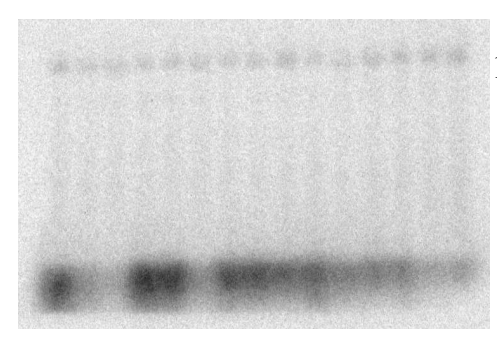

C $t f b 1$ antisense vs sense sRNA

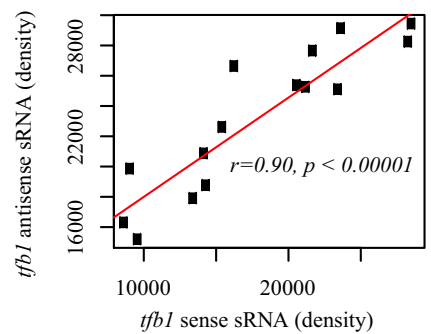

1000

B probe of antisense

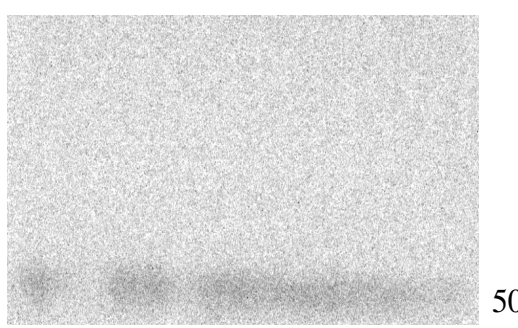

D $t f b 1$ sense sRNA vs mRNA

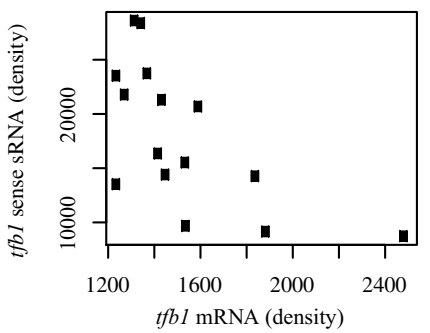

E $t f b l$ antisense sRNA vs mRNA

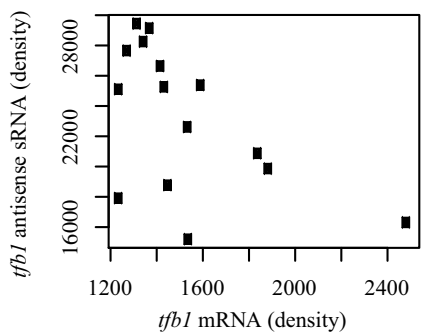

FIGURE 5 | Northern blot analysis of tfb1 from Pyrobaculum aerophilum using probes to the sense strand of $t f b(A)$ and antisense strand (B). Sense transcripts of $t f b 1$ occur at both full length ( 1000 nt) and at $50 \mathrm{nt}$. Antisense transcripts occur at $\sim 50 \mathrm{nt}$. Lanes 1-15 (upper panels, left to right); total RNA across five respiratory growth conditions in three time series.

Lanes 1-3 stationary phase, Lanes 4-6 growth with $\mathrm{O}_{2}, 7-9$ growth with $\mathrm{NO}_{3}$, 10-12 growth with As(V), 13-15 Fe(III). Each set of three lanes extracted from a time series for all five respiratory conditions at $T=(2.5,4.5,7.5 \mathrm{~h})$ with indicated terminal electron acceptor. Sense and antisense sRNA transcript abundance, inferred from band density, is positively correlated across growth conditions (C), while no significant correlation is found between full length tfb1 mRNA and either sRNA population (D,E). Full length tfb1 transcripts [1000 nt] remain nearly constant under all conditions tested (A). Band density established using imagej (http://rsb.info.nih.gov/ij/). terminates just upstream of the fur translation start codon. Both the asR2 transcript and a complementary RNA fragment apparently derived from the $5^{\prime}$ end of fur mRNA, were present at high levels in anaerobically grown $P$. aerophilum and at modest levels in $P$. calidifontis. In the strict anaerobes ( $P$. islandicum, $P$. arsenaticum), it appears that sequencing depth was insufficient to resolve any antisense-sense pairs under the limited set of growth conditions; however, we note that the predicted promoter for asR2 in the facultative aerobes is equally well-conserved across all Pyrobaculum species.

\section{THE TRIOSE-PHOSPHATE ISOMERASE (tpi) GENE}

The tpi gene encodes triose-phosphate isomerase, an enzyme that is central to the modified Embden-Meyerhoff glycolytic pathway in Pyrobaculum species (Reher et al., 2007). We detected a 65nt-long antisense transcript asR3 (Table A2 in Appendix) that overlaps the $3^{\prime}$ end of the tpi gene (Figure 4C) in all four of the species examined. Upon further examination of the $3^{\prime}$ terminal portion of tpi, we also detected a conserved sequence and associated secondary structure that is present in all sequenced Pyrobaculum spp. (Figure 6), which we term the tpi-element. In $P$. aerophilum, $P$. islandicum, and $P$. calidifontis, the tpi-element includes the stop codon of $t p i$, while the entire element is encoded immediately downstream of the tpi stop codon in the remaining Pyrobaculum spp.

A dsRNA formed by an interaction of asR3 with the tpi-element could potentially compete against the mRNA intramolecular structure, and thus modulate function of the highly conserved tpi-element. Alternatively, asR3 might itself be the active element of the pair, and in that case, presence of free tpi transcript might act as a repressor of $a s R 3$. In this model, asR3 may have other trans targets in the genome and play a more general role in coordination of glycolysis in Pyrobaculum species.

\section{DISCUSSION}

Comparative transcriptomics has revealed compelling, conserved cases of novel cis-encoded transcripts that are antisense to core protein coding genes involved in transcription initiation and metabolism. We have considered these most obviously as potential regulators of their opposite strand partners, but they might also have broader regulatory roles.

We found that 28 of the top 34 cases of conserved $3^{\prime}$ antisense expression among orthologous Pyrobaculum proteins of known function coincide with convergent $\mathrm{C} / \mathrm{D}$ box guide RNAs. This finding suggests that guide directed $2^{\prime}-O$-methylation of the mRNA in the region or downstream of the stop codon might be an unrecognized component of mRNA metabolism and gene regulation. It has been shown that pseudouridine modification of a stop codon can suppress termination of translation (Karijolich and Yu, 2011), but there are currently no studies of the possible implications of 2 '-O-methyl modification on mRNA translation or stability. Alternatively, the presence of abundant mRNA fragments at the $3^{\prime}$ end may indicate that a sense-antisense interaction between the C/D box sRNA and mRNA terminus results in truncation of the mRNA 


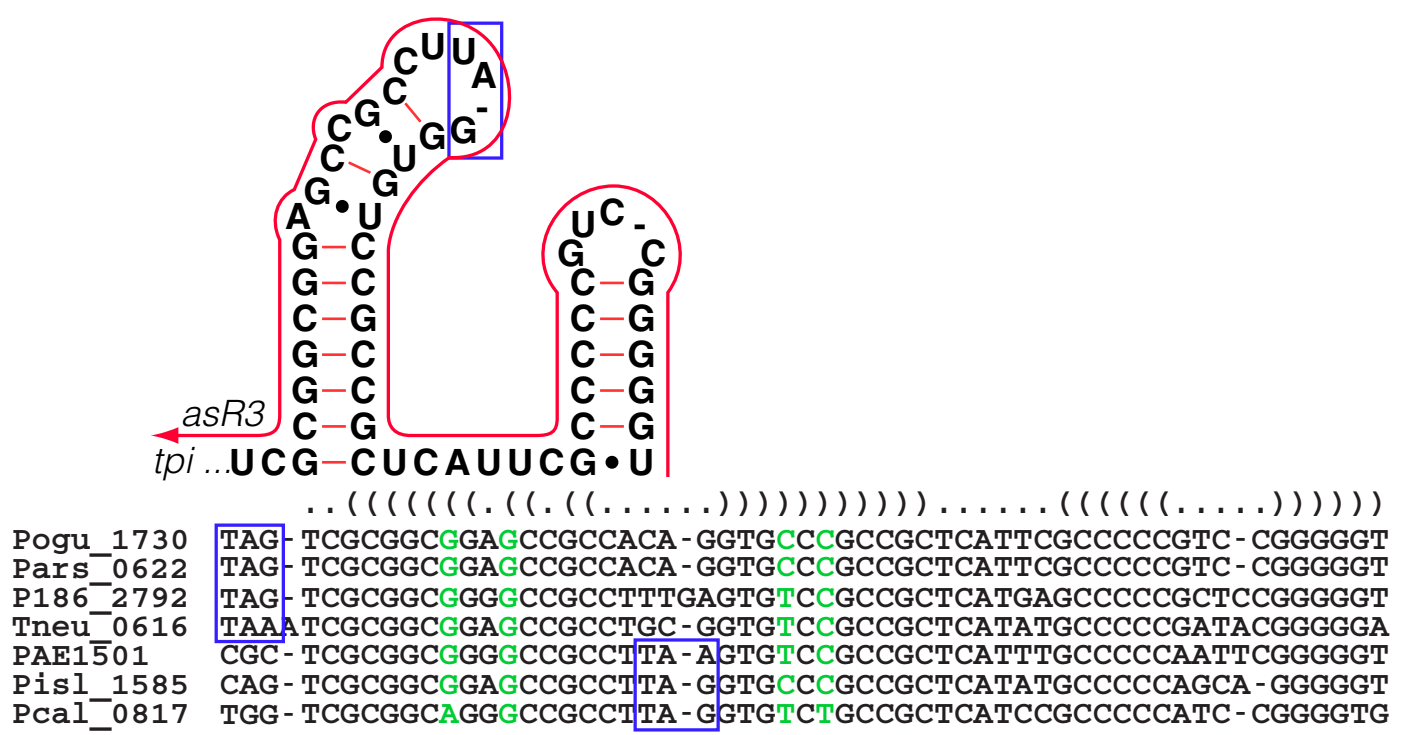

FIGURE 6 |The Pyrobaculum tpi-element and the associated antisense element, asR3. In all sequenced Pyrobaculum species, a highly conserved primary sequence forms a predicted secondary structure element (upper panel) at the $3^{\prime}$ end of the triose-phosphate isomerase gene (tpi). The depicted secondary structure contains the stop codon (blue box) in $P$. aerophilum (PAE1501), P. islandicum (Pisl_1585), and P. calidifontis

(Pcal_0817). In P. oguniense (Pogu_1730), P. arsenaticum (Pars_0622),
Pyrobaculum sp.1860 (P186_2792), and P. neutrophilum (Tneu 0616), the stop codon is immediately upstream of the tpi-element. asR3 (red line) is encoded on the opposite strand, and has potential to compete/interfere with the tpi-element secondary structure. The genomic alignment of the $3^{\prime}$ portion of tpi and 3' UTR is shown with the consensus secondary structure (nested parentheses). Base paired columns with one or more substitutions that maintain secondary structure are highlighted (green). by an unknown mechanism, leading to mRNA destabilization and degradation.

The coordinated regulatory program implemented by Fur and its regulatory sRNA $r y h B$ in some bacteria, provides a mechanism that yields both repression of some genes and activation (de-repression) of others. This program balances the needs of iron storage and utilization while protecting from iron-induced toxicity under oxic conditions. These dual roles are mediated by the inverse expression patterns of Fur and $r y h B$. Fur negatively regulates $r y h B$, which negatively regulates downstream genes. This circuit allows Fur to derepress (activate) those downstream genes. In published studies, active transcription in one direction can negatively regulate expression of the cis-encoded antisense partner (Lapidot and Pilpel, 2006), thus creating exclusive access to the shared genomic region. Likewise in Pyrobaculum, the cis-antisense transcription observed may yield the same type of inverse expression pattern. In this view, if the cis-antisense gene product is capable of repressing transcription or translation of targets in trans, then positive expression of Pyrobaculum fur, $t f b 1$, or $t p i$ may act through their corresponding antisense partner to activate (derepress) additional members of the associated regulon. Identification and verification of targets in trans is difficult in species that are not amenable to genetic manipulation such as Pyrobaculum, although future studies will explore computationally predicted targets.

The presence of asR1, a cis-encoded antisense RNA found within $t f b 1$ but not $t f b 2$ is of special interest when we consider these possible models of action for the cis-encoded antisense RNA. A specific TFB and TATA binding protein (TBP) pair in the archaeal halophile Halobacterium sp. NRC-1 has been shown to activate transcription under heat shock conditions (Coker and DasSarma, 2007). The observations that there are two instances of $t f b$ in all Pyrobaculum genomes, and that only one harbors an antisense gene, suggest that $t f b 1$ might be essential only under particular conditions and/or initiate transcription for a subset of Pyrobaculum genes. Under this model, $t f b l$ transcription might be held at low levels by the presence of asR 1 and possibly a dsRNA-binding complex. Under the alternative view, the cis-encoded asR1 might facilitate activation of a trans-encoded regulon via de-repression. In the former view, the mechanism(s) that regulate sRNA transcription, stability, and mRNA interaction are central, while in the latter model, the sRNA is a downstream effector molecule of the independently regulated top-strand mRNA partner. In either case, resolving the molecular details of the sRNA's interaction with $t f b 1$ are needed to better understand this potential high-level mechanism for broad gene regulation in Pyrobaculum.

The tpi-element and its associated antisense partner, asR3, may provide a novel regulatory circuit acting from the $3^{\prime}$ UTR of $t p i$. The structure of the tpi-element (Figures 4C and 6) contains the stop codon in some species while in other species the conserved structure is just downstream of the tpi stop codon. Possibilities for the function of the tpi-element include early transcription termination or translation termination. In either case, the tpielement could be acting as a novel $3^{\prime}$ UTR riboswitch by binding a small molecule, or alternatively may be involved in a proteinbinding event. Just as described above, the cis-antisense element asR3, encoded opposite the tpi-element, may act as a repressor of tpi-element function, or may have a role in trans with other genes in the tpi regulon. 
In this study, we have described 74 or more expressed C/D box sRNA in each of four transcriptomes, most of which are conserved among multiple Pyrobaculum species. We have shown evidence that an unexpectedly large number of these sRNA overlap protein coding genes. Three novel sRNAs asR1, asR2, and asR3 overlap genes involved in core transcription, iron regulation and core metabolism. Sequencing data have revealed the presence of sRNA originating from both strands, and these transcripts can be supported by promoter analysis, and verified by northern analyses. By contrast, less than $1 \%$ of transcripts mapped to CRISPR arrays show any evidence of dual strand transcripts (Figure 1). We suggest that the presence of dual-stranded transcript reads is an indication of an interaction of an sRNA with a convergently oriented mRNA, potentially mediated by one or more unknown dsRNA-binding complexes.

Future RNA-seq studies employing deeper sequencing technologies, alternative growth conditions, and other archaeal species will likely uncover many more cases of candidate regulatory antisense RNA. This work suggests multiple new research directions and will require complementary methodologies to better understand the complexity of sRNA function in Archaea. Given the conserved patterns of cis-antisense RNA transcripts now apparent, we anticipate rapid progress from follow-up studies that will demonstrate new modes of gene regulation homologous or analogous to those found in bacteria and eukaryotes.

\section{REFERENCES}

Aiba, H. (2007). Mechanism of RNA silencing by Hfa-binding small RNAs. Curr. Opin. Microbiol. 10, 134-139.

Altschul, S. F., Gish, W., Miller, W., Myers, E. W., and Lipman, D. J. (1990). Basic local alignment search tool. J. Mol. Biol. 215, 403-410.

Andrews, S. C., Robinson, A. K., and Rodriguez-Quinones, F. (2003). Bacterial iron homeostasis. FEMS Microbiol. Rev. 27, 215-237.

Barrangou, R., Fremaux, C., Deveau, H., Richards, M., Boyaval, P., Moineau, S., Romero, D. A., and Horvath, P. (2007). CRISPR provides acquired resistance against viruses in prokaryotes. Science 315, 1709-1712.

Bernick, D. L., Dennis, P. P., Hochsmann, M., and Lowe, T. M. (2012). Discovery of Pyrobaculum small RNA families with atypical pseudouridine guide RNA features. RNA 18, 402-411.

Camacho, C., Coulouris, G., Avagyan, V., Ma, N., Papadopoulos, J., Bealer, K., and Madden, T. L. (2009). BLAST+: architecture and applications. BMC Bioinformatics 10, 421. doi:10.1186/1471-2105-10-421

Chan, P. P., Holmes, A. D., Smith, A. M., Tran, D., and Lowe, T. M. (2012). The UCSC Archaeal Genome Browser: 2012 update. Nucleic Acids Res. 40, D646-D652.

Coker, J. A., and DasSarma, S. (2007). Genetic and transcriptomic analysis RNA-Cas protein complex. Cell 139,

\section{ACKNOWLEDGMENTS}

We are grateful to members of the Joint Genome Institute for making 454 sequencing possible (P. Richardson and J. Bristow for providing resources, and E. Lindquist and N. Zvenigorodsky for sample preparation and analysis). We thank Aaron Cozen for his generous procedural guidance and for the use of RNA blots used in the study. This work was supported by National Science Foundation Grant EF-082277055 (Todd M. Lowe and David L. Bernick); the Graduate Research and Education in Adaptive Bio-Technology (GREAT) Training Program sponsored by the University of California Bio-technology Research and Education Program (David L. Bernick); and by the National Science Foundation while Patrick P. Dennis was working at the Foundation. The opinions, findings, and conclusion expressed in this publications are ours and do not necessarily reflect the views of the National Science Foundation.

\section{AUTHOR CONTRIBUTIONS}

David L. Bernick designed and performed the experimental and computational analyses, and wrote the manuscript. Lauren M. Lui analyzed the C/D box sRNA sequencing data. Patrick P. Dennis provided assistance with the manuscript, collaborative review, and structure determination of C/D box sRNA. Todd M. Lowe provided scientific direction, contributed to interpretation of results, and edited the manuscript.

gene silencing and DNA methylation

of transcription factor genes in the model halophilic archaeon: coordinate action of TbpD and TfbA. BMC Genet. 8, 61. doi:10.1186/1471-21568-61

Cozen, A. E., Weirauch, M. T., Pollard, K. S., Bernick, D. L., Stuart, J. M., and Lowe, T. M. (2009). Transcriptional map of respiratory versatility in the hyperthermophilic crenarchaeon Pyrobaculum aerophilum. J. Bacteriol. 191, 782-794.

Dennis, P. P., Omer, A., and Lowe, T. (2001). A guided tour: small RNA function in archaea. Mol. Microbiol. 40, 509-519.

Fitz-Gibbon, S. T., Ladner, H., Kim, U. J., Stetter, K. O., Simon, M. I., and Miller, J. H. (2002). Genome sequence of the hyperthermophilic crenarchaeon Pyrobaculum aerophilum. Proc. Natl. Acad. Sci. U.S.A. 99, 984-989.

Hale, C., Kleppe, K., Terns, R. M., and Terns, M. P. (2008). Prokaryotic silencing (psi)RNAs in Pyrococcus furiosus. RNA 14, 2572-2579.

Hale, C. R., Zhao, P., Olson, S., Duff, M. O., Graveley, B. R., Wells, L., Terns, R. M., and Terns, M. P. (2009). RNAguided RNA cleavage by a CRISPR 945-956.

Henderson, I. R., Zhang, X., Lu, C., Johnson, L., Meyers, B. C., Green, P. J., and Jacobsen, S. E. (2006). Dissecting Arabidopsis thaliana DICER function in small RNA processing, patterning. Nat. Genet. 38, 721-725.

Masse, E., Salvail, H., Desnoyers, G., and Arguin, M. (2007). Small RNAs controlling iron metabolism. Curr. Opin. Microbiol. 10, 140-145.

(1), Sharma, C. M., Thomsen,

Ehlers, C., Vogel, J., and Schmitz,

R. A. (2009). Deep sequencing

analysis of the Methanosarcina

mazei Gol transcriptome in response to nitrogen availability. Proc. Natl. Acad. Sci. U.S.A. 106, 21878-21882.

Karijolich, J., and Yu, Y. T. (2011). Converting nonsense codons into sense codons by targeted pseudouridylation. Nature 474, 395-398.

Kent, W. J. (2002). BLAT - the BLASTlike alignment tool. Genome Res. 12, 656-664.

Lapidot, M., and Pilpel, Y. (2006). Genome-wide natural antisense transcription: coupling its regulation to its different regulatory mechanisms. EMBO Rep. 7, 1216-1222.

Lau, N. C., Lim, L. P., Weinstein, E. G., and Bartel, D. P. (2001). An abundant class of tiny RNAs with probable regulatory roles in Caenorhabditis elegans. Science 294, 858-862.

Lu, C., Kulkarni, K., Souret, F. F., Muthuvalliappan, R., Tej, S. S., Poethig, R. S., Henderson, I. R., Jacobsen, S. E., Wang, W., Green, P. J., and Meyers, B. C. (2006). MicroRNAs and other small RNAs enriched in the Arabidopsis RNA-dependent RNA polymerase-2 mutant. Genome Res. $16,1276-1288$.
Omer, A. D., Lowe, T. M., Russell, A. G., Ebhardt, H., Eddy, S. R., and Dennis, P. P. (2000). Homologs of small nucleolar RNAs in Archaea. Science 288, 517-522.

Pak, J., and Fire, A. (2007). Distinct populations of primary and secondary effectors during RNAi in C. elegans. Science 315, 241-244.

Reher, M., Gebhard, S., and Schonheit, P. (2007). Glyceraldehyde-3phosphate ferredoxin oxidoreductase (GAPOR) and nonphosphorylating glyceraldehyde-3-phosphate dehydrogenase (GAPN), key enzymes of the respective modified Embden-Meyerhof pathways in the hyperthermophilic crenarchaeota Pyrobaculum aerophilum and Aeropyrum pernix. FEMS Microbiol. Lett. 273, 196-205.

Repoila, F., Majdalani, N., and Gottesman, S. (2003). Small non-coding RNAs, co-ordinators of adaptation processes in Escherichia coli: the RpoS paradigm. Mol. Microbiol. 48, 855-861.

Santangelo, T. J., Cubonova, L., James, C. L., and Reeve, J. N. (2007). TFB1 or TFB2 is sufficient for Thermococcus kodakaraensis viability and for basal transcription in vitro. J. Mol. Biol. 367, 344-357. 
Straub, J., Brenneis, M., Jellen-Ritter, A., Heyer, R., Soppa, J., and Marchfelder, A. (2009). Small RNAs in haloarchaea: identification, differential expression and biological function. RNA Biol. 6, 281-292.

Tang, T. H., Bachellerie, J. P., Rozhdestvensky, T., Bortolin, M. L., Huber, H., Drungowski, M., Elge, T., Brosius, J., and Huttenhofer, A. (2002). Identification of 86 candidates for small nonmessenger RNAs from the archaeon Archaeoglobus fulgidus. Proc. Natl. Acad. Sci. U.S.A. 99, 7536-7541.

Tang, T. H., Polacek, N., Zywicki, M., Huber, H., Brugger, K., Garrett, R., Bachellerie, J. P., and Huttenhofer, A. (2005). Identification of novel non-coding RNAs as potential antisense regulators in the archaeon Sulfolobus solfataricus. Mol. Microbiol. $55,469-481$.

Vogel, J. (2009). A rough guide to the non-coding RNA world of Salmonella. Mol. Microbiol. 71, 1-11.

Wilderman, P. J., Sowa, N. A., Fitzgerald, D. J., Fitzgerald, P. C., Gottesman, S., Ochsner, U. A., and Vasil, M. L. (2004). Identification of tandem duplicate regulatory small RNAs in Pseudomonas aeruginosa involved in iron homeostasis. Proc. Natl. Acad. Sci. U.S.A. 101, 9792-9797.

Wurtzel, O., Sapra, R., Chen, F., Zhu, Y., Simmons, B. A., and Sorek, R. (2010). A single-base resolution map of an archaeal transcriptome. Genome Res. 20, 133-141.

Zago, M. A., Dennis, P. P., and Omer, A. D. (2005). The expanding world of small RNAs in the hyperthermophilic archaeon Sulfolobus solfataricus. Mol. Microbiol. $55,1812-1828$.

Conflict of Interest Statement: The authors declare that the research was conducted in the absence of any commercial or financial relationships that could be construed as a potential conflict of interest.

Received: 28 April 2012; accepted: 06 June 2012; published online: 02 July 2012.
Citation: Bernick DL, Dennis PP, Lui LM and Lowe TM (2012) Diversity of antisense and other non-coding RNAs in archaea revealed by comparative small RNA sequencing in four Pyrobaculum species. Front. Microbio. 3:231. doi: 10.3389/fmicb.2012.00231

This article was submitted to Frontiers in Evolutionary and Genomic Microbiology, a specialty of Frontiers in Microbiology.

Copyright (c) 2012 Bernick, Dennis, Lui and Lowe. This is an openaccess article distributed under the terms of the Creative Commons Attribution Non Commercial License, which permits non-commercial use, distribution, and reproduction in other forums, provided the original authors and source are credited. 


\section{APPENDIX}

Table A1 | Orthologous genes with 5' sequencing reads. Orthologous groups are shown in each row where the locus tag number (e.g., 1645 for gene PAE1645) is followed by counts of (antisense, sense) reads. Groups are ranked by the total number of reads found within groupings formed by the number of species in a group with antisense sequencing reads. Read counts are accumulated by considering the largest region covered by at least one read in an overlapping region along a given strand, and assigning the read count to that region. Footnoted gene IDs have associated snoRNA-like sRNA (C/D box or H/ACA-like) - a, antisense oriented; s, sense oriented.

\begin{tabular}{|c|c|c|c|c|}
\hline Product & P. aerophilum & P. arsenaticum & P. calidifontis & P. islandicum \\
\hline Transcription initiation factor IIB & $1645(225,409)$ & $1976(12,16)$ & $0584(1,1)$ & $1667(8,39)$ \\
\hline DNA-cytosine methyltransferase & $1659(4,0)$ & $1839(1,0)$ & 0576 & $1675(2,0)$ \\
\hline Rhomboid family protein & $1099(3,0)$ & $0267(1,0)$ & 0686 & $1249(2,0)$ \\
\hline Ferric uptake regulator, Fur family & $2309(40,11)$ & 1526 & $1653(1,0)$ & 1023 \\
\hline $30 \mathrm{~S}$ ribosomal protein $\mathrm{S} 12 \mathrm{P}$ & 0670 & $2326(2,0)$ & 2096 & $0698(7,1)$ \\
\hline Cobalamin adenosyltransferase & 1715 & 0782 & $0623^{a}(86,4)$ & $1701(0,3)$ \\
\hline Thiol:disulfide interchange protein & 3152 & 1672 & 1794 & $0523(32,0)$ \\
\hline 30 S ribosomal protein S11P & $3179(15,2)$ & $1654(0,2)$ & 1813 & 0540 \\
\hline NAD-dependent deacetylase & 3500 & $1959^{a}(12,3)$ & 1963 & 0793 \\
\hline NADH dehydrogenase subunit A & $3520(9,0)$ & $1954(0,1)$ & 1983 & 0847 \\
\hline 30 S ribosomal protein S3P & 1779 & 0769 & 0553 & $1729(9,0)$ \\
\hline Translation initiation factor IF-1A & $1072(7,0)$ & 0278 & 0681 & 1256 \\
\hline Putative transcriptional regulator, GntR family & $2315(0,10)$ & $1532(4,2)$ & $1659(0,2)$ & 1028 \\
\hline Valyl-tRNA synthetase & $2297(4,0)$ & $1497(0,1)$ & 1649 & $1019(0,1)$ \\
\hline Putative signal-transduction protein with CBS domains & $2961(4,0)$ & $1332(0,1)$ & 1143 & 0364 \\
\hline Major facilitator superfamily MFS_1 & $1550^{\mathrm{s}}(3,5)$ & $0660^{\mathrm{s}}(0,2)$ & $0530^{s}(0,2)$ & \\
\hline Elongation factor 1 , beta/beta'/delta chain & $0695(3,1)$ & 2345 & 2114 & 0684 \\
\hline Egghead-like protein & $0042(3,2)$ & 1076 & $2043(0,1)$ & 0056 \\
\hline V-type ATP synthase subunit B & 1146 & $0237(3,0)$ & 0698 & 1264 \\
\hline Conserved protein (possible ATP binding) & $0793(3,11)$ & 0044 & 2138 & 1084 \\
\hline Putative transcriptional regulator, ModE family & $0813(2,0)$ & 0057 & 0023 & 1100 \\
\hline $50 S$ ribosomal protein L18e & 0672 & $2328(2,0)$ & 2098 & $0696(0,1)$ \\
\hline ABC transporter related & $1393(2,0)$ & 0445 & 1879 & 1525 \\
\hline Peptidase M50 & 1702 & $2238(2,1)$ & 0618 & 1696 \\
\hline Cation diffusion facilitator family transporter & $0568(2,0)$ & 2239 & 1215 & $0125(0,2)$ \\
\hline paREP10 & 1480 & $0613(2,0)$ & $0811(0,1)$ & 1575 \\
\hline Exosome complex RNA-binding protein Rrp42 & $2206(2,1)$ & 1938 & 0932 & 0835 \\
\hline Inner-membrane translocator & $3412(2,0)$ & 1174 & 1046 & 0977 \\
\hline NADH-ubiquinone oxidoreductase subunit & & 2274 & 2047 & $0329(1,0)$ \\
\hline CopG domain protein DNA-binding domain protein & $2357(1,0)$ & 1561 & 1689 & 0622 \\
\hline Inner-membrane translocator & $3348(1,0)$ & 1760 & 0444 & 0590 \\
\hline Amino acid-binding ACT domain protein & 2296 & 1510 & 1648 & $1018(1,1)$ \\
\hline Hydrogen sulfite reductase & $2596(1,0)$ & 1213 & 1457 & \\
\hline DNA-directed RNA polymerase subunit P & $2258(0,1)$ & 1825 & $1624(1,0)$ & 0899 \\
\hline DNA polymerase, beta domain protein & 1893 & $0821(1,0)$ & 1502 & \\
\hline Phosphate $A B C$ transporter, inner membrane subunit PstC & 1396 & 0443 & 1881 & $1527(1,0)$ \\
\hline Nicotinamide-nucleotide adenylyltransferase & 1438 & $0405(1,0)$ & 0794 & 1561 \\
\hline Peptidase S8 and S53, subtilisin, kexin, sedolisin & 1983 & 2056 & & $1805(1,0)$ \\
\hline Glu/Leu/Phe/Val dehydrogenase,C terminal & 3438 & 1871 & 1031 & $0980(1,0)$ \\
\hline D-isomer specific 2-hydroxyacid dehydrogenase, NAD-binding & $3320(1,1)$ & 1736 & 1741 & 0566 \\
\hline Electron transfer flavoprotein, alpha subunit & 0721 & $2372(1,0)$ & 2132 & $0645(0,1)$ \\
\hline Sua5/YciO/YrdC/YwlC family protein & $2978(1,0)$ & 1345 & 1129 & $0378(0,1)$ \\
\hline AAA ATPase & 3527 & $1626(1,0)$ & 1978 & 0145 \\
\hline MazG nucleotide pyrophosphohydrolase & $1159(1,0)$ & 0222 & 0722 & \\
\hline 30 S ribosomal protein S8P & 2098 & $2009(0,2)$ & 0176 & $1865(1,0)$ \\
\hline Transcriptional regulator, XRE family & 0783 & $0037(1,0)$ & 2145 & 1076 \\
\hline
\end{tabular}


Table A1 | Continued

\begin{tabular}{|c|c|c|c|c|}
\hline Product & P. aerophilum & P. arsenaticum & P. calidifontis & P. islandicum \\
\hline Acyl-CoA dehydrogenase domain protein & 2070 & 2103 & 0199 & $1853(1,0)$ \\
\hline 2-dehydropantoate 2-reductase & $3409(1,0)$ & 2003 & 0383 & 1363 \\
\hline FHA domain containing protein & 0816 & $0060(1,0)$ & 0026 & 1103 \\
\hline PaREP1 domain containing protein & 3235 & & $0464(0,3)$ & $1514(1,0)$ \\
\hline $30 S$ ribosomal protein $\mathrm{S} 19 \mathrm{e}$ & $3043(1,1)$ & 1790 & 0988 & $0440(0,39)$ \\
\hline CutA1 divalent ion tolerance protein & 2325 & 1539 & 1667 & $1044(1,0)$ \\
\hline Nitrilase/cyanide hydratase and apolipoprotein N-acyltransferase & $2075(1,1)$ & 2019 & 0203 & 1857 \\
\hline Inner-membrane translocator & $2083(1,0)$ & 1504 & 0826 & $0317(0,2)$ \\
\hline 30 S ribosomal protein S7P & $0733(1,1)$ & 0001 & 0006 & $0655(0,3)$ \\
\hline Ribosomal protein L11 & $3104(1,0)$ & 1602 & 1832 & 0464 \\
\hline Metallophosphoesterase & 3211 & $1639(1,0)$ & 0239 & 1924 \\
\hline Acetolactate synthase, large subunit, biosynthetic type & 3300 & $1724(1,1)$ & 1753 & $0554(0,2)$ \\
\hline NAD+ synthetase & $1219(0,1)$ & $0310(1,0)$ & 0793 & 1302 \\
\hline $30 \mathrm{~S}$ ribosomal protein S3Ae & $3472(1,0)$ & 1852 & 1182 & $0771(0,1)$ \\
\hline Band7 protein & 0750 & 0015 & $2166(1,0)$ & 1055 \\
\hline TGS domain protein & 1649 & 1844 & 0581 & $1670(1,0)$ \\
\hline MoaD family protein & $0727(0,1)$ & 2368 & $2136(1,0)$ & 0649 \\
\hline Putative circadian clock protein, KaiC & $0729(1,1)$ & $2366(0,2)$ & 0010 & 0651 \\
\hline Tryptophanyl-tRNA synthetase & $3091(1,0)$ & 1612 & 1822 & 0454 \\
\hline Aldehyde ferredoxin oxidoreductase & $0622(1,4)$ & 2285 & 2057 & 0738 \\
\hline Inner-membrane translocator & 3350 & 1761 & $0445(0,1)$ & $0591(1,0)$ \\
\hline Tyrosyl-tRNA synthetase & 0630 & $2290(1,0)$ & 2062 & 0733 \\
\hline NADH-quinone oxidoreductase, B subunit & 2928 & 1001 & 1957 & $0336(1,0)$ \\
\hline Prephenate dehydratase & $0893^{s}(0,51)$ & 0111 & 0075 & $1150(1,0)$ \\
\hline
\end{tabular}


Table A2 | Orthologous genes with 3' sequencing reads. Orthologous groups, read counts, and footnotes displayed are as described in Table A1.

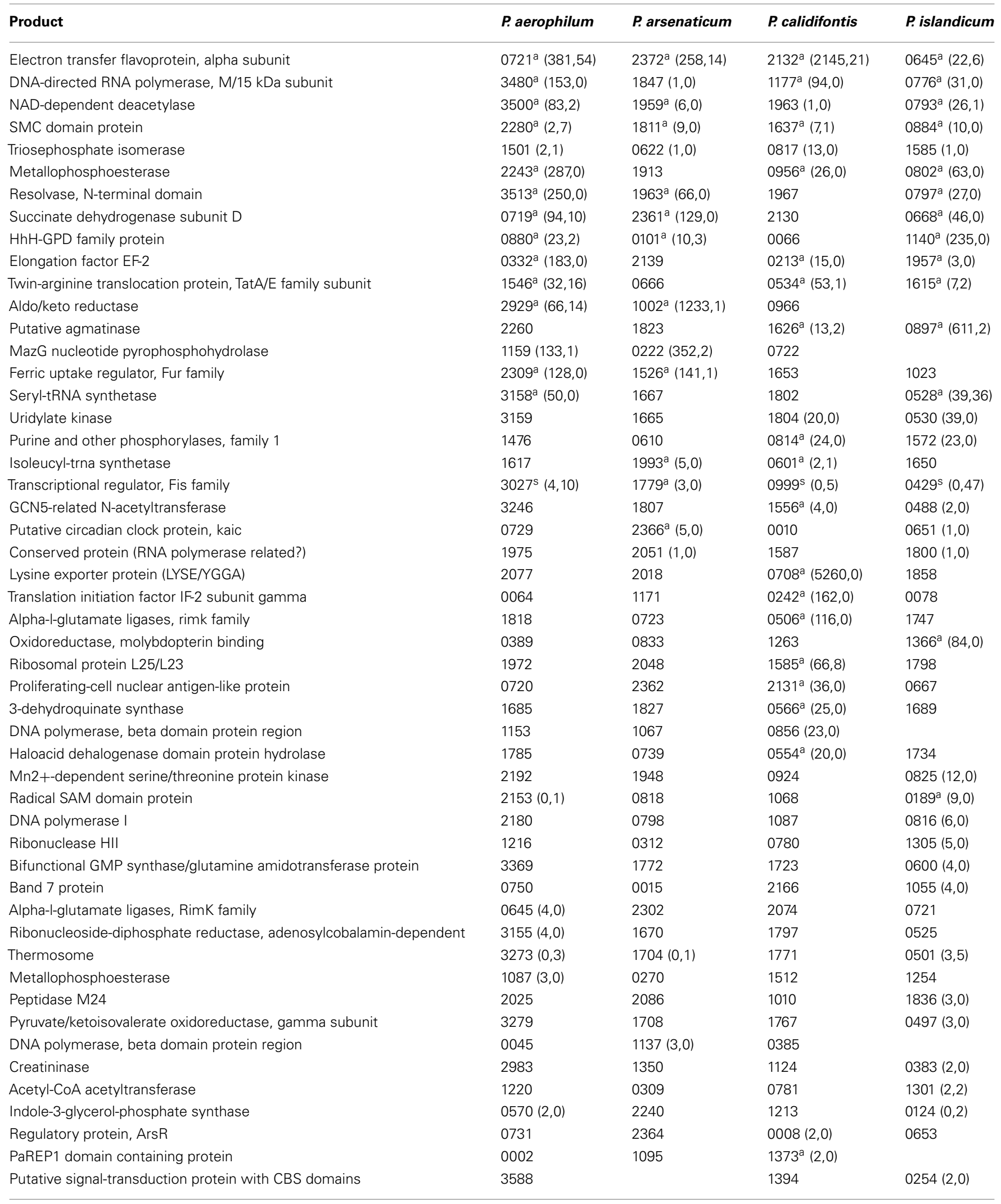


Table A2 | Continued

\begin{tabular}{|c|c|c|c|c|}
\hline Product & P. aerophilum & P. arsenaticum & P. calidifontis & P. islandicum \\
\hline Exosome complex exonuclease Rrp41 & $2207(2,1)$ & 1937 & 0933 & 0836 \\
\hline$A B C$ transporter related & $3413(2,0)$ & 1175 & 1045 & 0976 \\
\hline Potassium transport membrane protein, conjectural & $2422(2,0)$ & 1446 & 0314 & 0883 \\
\hline Undecaprenyl diphosphate synthase & $2942(2,0)$ & 1319 & 1157 & 0348 \\
\hline Carboxypeptidase Taq & $0885(1,2)$ & 0104 & $0069(0,1)$ & 1143 \\
\hline Leucyl-tRNA synthetase & 1107 & 0260 & 0691 & $1246(1,0)$ \\
\hline HEPN domain protein & 1894 & $0820(1,0)$ & 1501 & \\
\hline DNA-directed RNA polymerase subunit E, RpoE2 & $3563(1,0)$ & 2230 & 1991 & 0921 \\
\hline 5-carboxymethyl-2-hydroxymuconate $\Delta$-isomerase & 2688 & 0535 & $1503(1,0)$ & \\
\hline Egghead-like protein & 0042 & 1076 & 2043 & $0056(1,0)$ \\
\hline Putative transcriptional regulator, CopG family & $1443(0,2)$ & 0399 & 0796 & $1563(1,1)$ \\
\hline Asparaginyl-tRNA synthetase & $2973(1,0)$ & 1342 & 1133 & 0375 \\
\hline Succinate dehydrogenase iron-sulfur subunit & 0717 & 2359 & 2128 & $0670(1,0)$ \\
\hline Peptidase T2, asparaginase 2 & $3083(1,0)$ & 1892 & 0970 & 0908 \\
\hline Radical SAM domain protein & 0596 & 2255 & 1716 & $0113(1,0)$ \\
\hline 30 S ribosomal protein $\mathrm{S} 25 \mathrm{e}$ & $2188(0,1)$ & $0790(0,1)$ & 1079 & $0808(1,0)$ \\
\hline Ribosomal-protein-alanine acetyltransferase & $2246(1,0)$ & & 0958 & 1001 \\
\hline PilT protein domain protein & $3561(1,0)$ & 1614 & 1989 & 0923 \\
\hline Peptidase S8 and S53, subtilisin, kexin, sedolisin & 0712 & 2355 & $2124(1,0)$ & 0674 \\
\hline Putative endoribonuclease L-PSP & $3003^{s}(1,62)$ & $1258^{\mathrm{s}}(0,210)$ & $1096^{\mathrm{s}}(0,81)$ & $0414^{\mathrm{s}}(0,65)$ \\
\hline Sulfite reductase, dissimilatory-type beta subunit & 2597 & $1212(1,0)$ & 1456 & \\
\hline Methyltransferase small & 0261 & 2199 & 0236 & $0747(1,0)$ \\
\hline Putative transcriptional regulator, AsnC family & $1507(1,0)$ & $0627(0,1)$ & 0822 & 1590 \\
\hline Methyltransferase type 11 & 1165 & $0216(1,0)$ & 1364 & 1338 \\
\hline Serine/threonine protein kinase & 0815 & $0059(1,0)$ & 0025 & 1102 \\
\hline Transcriptional regulator, PadR-like family & 0013 & $1087(1,0)$ & & 0038 \\
\hline Inner-membrane translocator & $3350(1,0)$ & 1761 & 0445 & 0591 \\
\hline Geranylgeranyl reductase & 2989 & 1355 & 1119 & $0388(1,0)$ \\
\hline Extracellular solute-binding protein, family 5 & 2391 & 1494 & 0422 & $0602(1,0)$ \\
\hline 2-methylcitrate synthase/citrate synthase II & $1689(1,0)$ & 2234 & 0563 & 1692 \\
\hline $30 \mathrm{~S}$ ribosomal protein S6e & $1505(0,1)$ & $0626(1,0)$ & 0821 & 1589 \\
\hline
\end{tabular}


Table A3 | Hypothetical genes with 5' sequencing reads. Orthologous groups, read counts, and footnotes displayed are as described in Table A1.

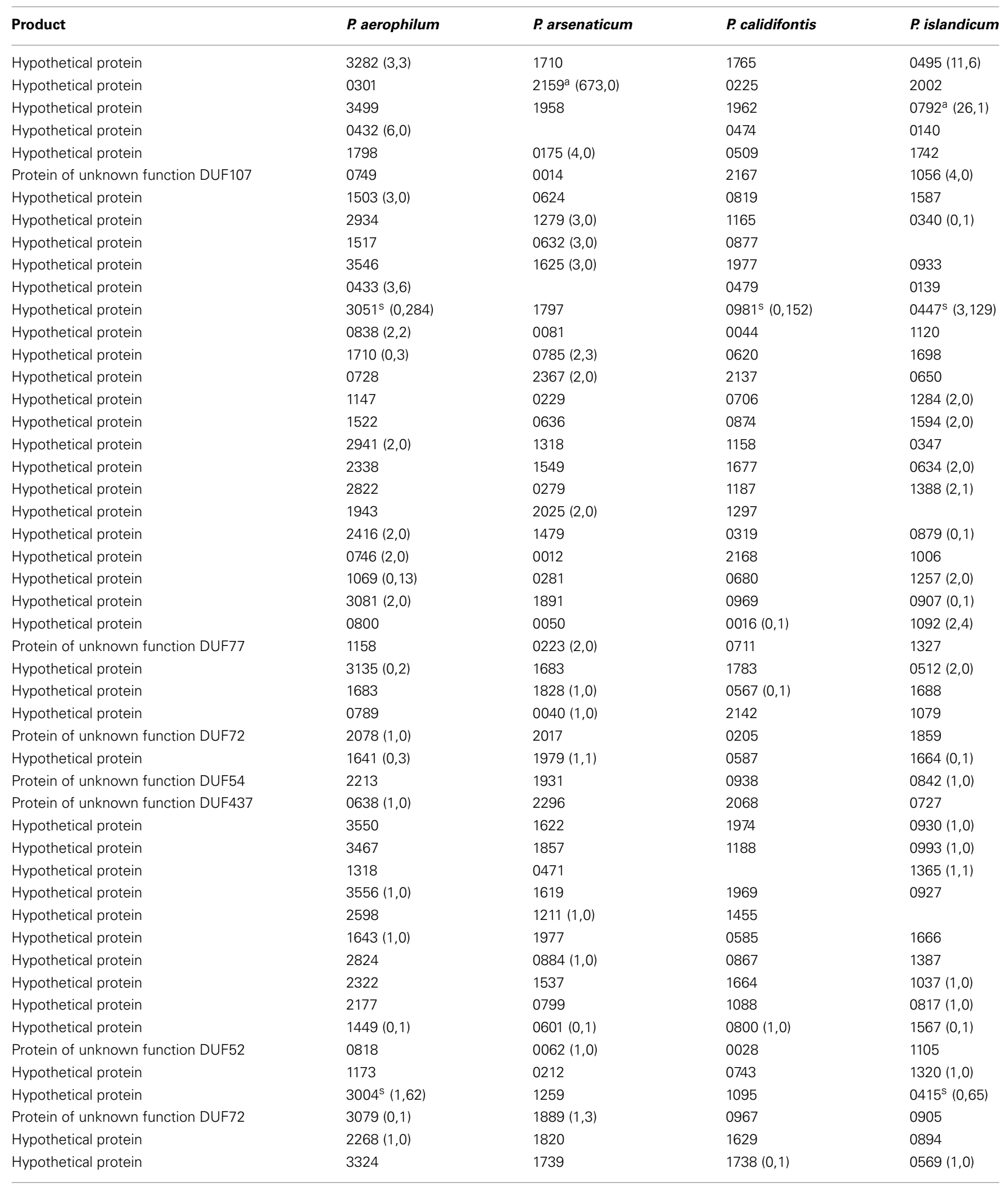


Table A3 | Continued

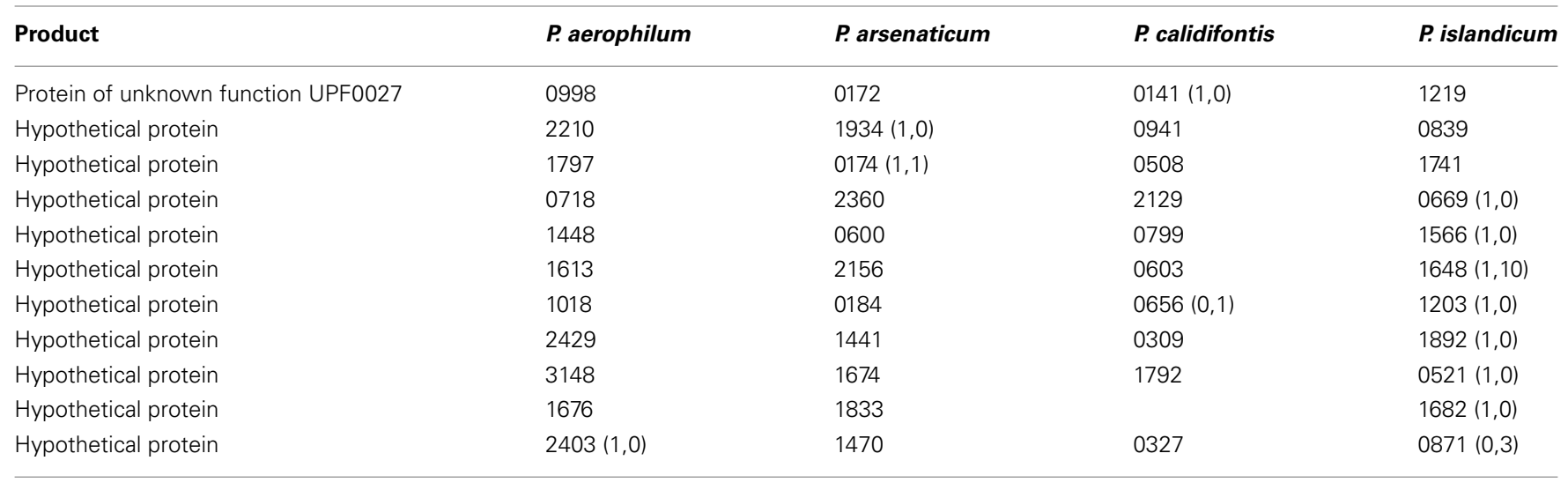


Table A4 | Hypothetical genes with 3' sequencing reads. Orthologous groups, read counts, and footnotes displayed are as described in Table A1.

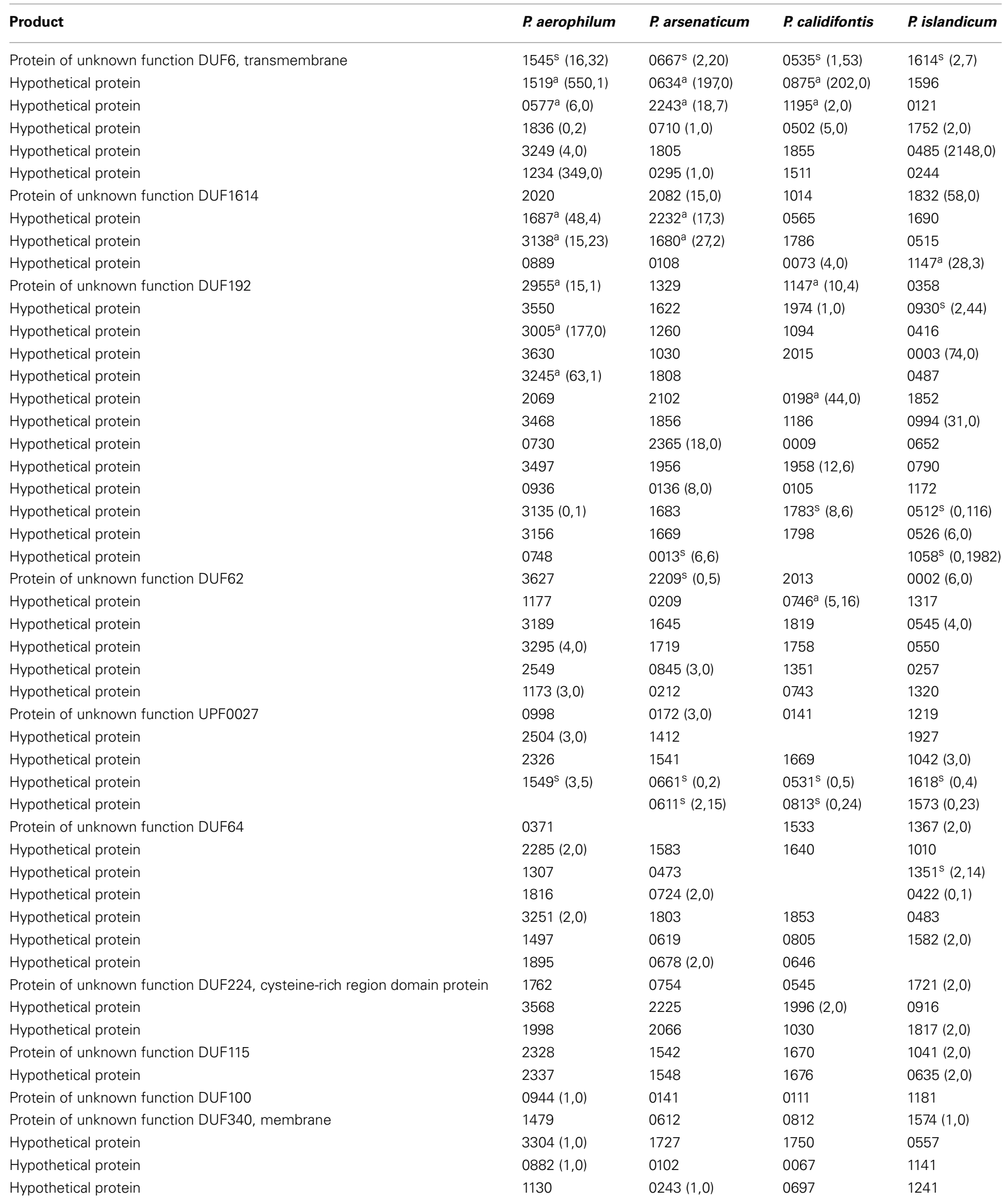


Table A4 | Continued

\begin{tabular}{llll}
\hline Product & P aerophilum & P. arsenaticum & P. calidifontis \\
\hline Hypothetical protein & 1449 & 0601 & 0800 \\
Hypothetical protein & 2190 & 1946 & 0927 \\
Hypothetical protein & $0927(1,0)$ & 0131 & 0083 \\
Hypothetical protein & 0708 & 2353 & 2122 \\
Hypothetical protein & 2606 & $1232(1,0)$ & 1431 \\
Hypothetical protein & 2187 & $0791(1,0)$ & 1080 \\
Hypothetical protein & 0239 & $1512(1,0)$ & 0690 \\
Protein of unknown function DUF1028 & 3380 & $1006(1,0)$ & 0160 \\
Hypothetical protein & $2154(1,0)$ & 0817 & 1069 \\
Hypothetical protein & 3161 & 1666 & 1069 \\
Hypothetical protein & 2058 & 2311 & $0676(1,0)$ \\
Hypothetical protein & 0840 & $0083(1,0)$ & 0401 \\
\hline
\end{tabular}

